\title{
Helicobacter pylori accelerates hepatic fibrosis by sensitizing transforming growth factor- $\beta 1$-induced inflammatory signaling
}

\author{
Mi-Ran Ki ${ }^{1}$, Moon-Jung Goo ${ }^{1}$, Jin-Kyu Park', Il-Hwa Hong ${ }^{1}$, Ae-Ri Ji ${ }^{1}$, Seon-Young Han ${ }^{1}$, Sang-Young You ${ }^{1}$, \\ Eun-Mi Lee ${ }^{1}$, Ah-Young Kim', Sang-Joon Park', Hyun-Joo Lee ${ }^{2}$, Shin-Yoon Kim² and Kyu-Shik Jeong ${ }^{1}$
}

Our earlier report has shown that Helicobacter pylori promoted hepatic fibrosis in a murine model. Herein, in order to elucidate the mechanism by which $H$. pylori accelerate liver fibrosis, the authors investigated the changes in expression levels of mitogen-activated protein kinases (MAPKs), p53-related proteins, antioxidants, and proinflammatory cytokines in liver samples. $\mathrm{H}$. pylori infection enhanced $\mathrm{CCl}_{4}$-induced MAP kinase activation and p53 signaling pathway as well as Bax- and proliferating-cell nuclear antigen expressions, whereas $H$. pylori alone induced neither of these expressions nor hepatic fibrosis. Moreover, mRNA expressions of inflammatory cytokines, glutathione peroxidase expression, and the proliferative index were strongly augmented in livers of the $\mathrm{H}$. pylori with $\mathrm{CCl}_{4}$ treatment group compared with those of the $\mathrm{CCl}_{4}$-alone treatment group, whereas there was no difference in apoptotic index between the two groups. Interestingly, $\mathrm{H}$. pylori treatment increased the number of $\alpha$-fetoprotein-expressing hepatocytes independently of $\mathrm{CCl}_{4}$ intoxication. In vitro analyses, using an immortalized rat hepatic stellate cell (HSC) line, revealed that $H$. pylori lysates increased the proliferation of HSCs, which was boosted by the addition of transforming growth factor-beta1 (TGF- $\beta 1$ ). Furthermore, the treatment of $\mathrm{H}$. pylori lysates promoted the translocation of nuclear factor kappa-light-chain enhancer of activated $\mathrm{B}$ cells (NF- $\kappa \mathrm{B}$ ) into the nucleus based on an increase in the degradation of NF- $\kappa \mathrm{B}$ inhibitor alpha, in the presence of TGF- $\beta 1$, as did $\mathrm{H}_{2} \mathrm{O}_{2}$ treatment. In conclusion, $H$. pylori infection along with an elevated TGF- $\beta 1$ may accelerate hepatic fibrosis through increased TGF- $\beta 1$-induced pro-inflammatory signaling pathways in HSCs. Moreover, H. pylori infection might increase the risk of TGF- $\beta 1$-mediated tumorigenesis by disturbing the balance between apoptosis and proliferation of hepatocytes.

Laboratory Investigation (2010) 90, 1507-1516; doi:10.1038/labinvest.2010.109; published online 7 June 2010

KEYWORDS: Helicobacter pylori; hepatic fibrosis; hepatic stellate cells; inflammation; TGF- $\beta 1$

Helicobacter pylori is one of the most common bacterial infections found in more than $50 \%$ of the human population worldwide. ${ }^{1,2}$ As $H$. pylori was first cultivated from human gastric biopsy specimens in 1982, it has been recognized as a causative agent in most of the gastroduodenal diseases, including peptic ulcer, gastric cancer, and gastric mucosa lymphoid tissue lymphoma. ${ }^{3-7}$ Furthermore, chronic $H$. pylori infection is related to various other gastric diseases, though the precise role of $H$. pylori is unknown in these diseases and there is still controversy regarding this association, including idiopathic thrombocytopenic purpura ${ }^{8}$ and cardiovascular disease. ${ }^{9}$ Elevated levels of C-reactive protein and IL-6 that are systemic inflammatory markers have been reported to predict the development of type 2 diabetes mellitus (DM). ${ }^{10}$ Association of $H$. pylori infection with systemic inflammation has also been reported. ${ }^{11,12}$ Recently, an interesting case report showed that $H$. pylori eradication therapy ameliorated type B insulin resistance syndrome, for which there is no established effective therapy. ${ }^{13}$ Reportedly, $H$. pylori infection occurs with a high frequency in patients with cirrhosis and hepatocellular carcinoma (HCC), which may explain the frequent occurrence of gastroduodenal ulcer in cirrhotic patients. ${ }^{14-17}$ Several studies have shown that $H$. pylori genomic sequences could be detected in the liver of

\footnotetext{
${ }^{1}$ Department of Pathology, College of Veterinary Medicine, Kyungpook National University, Daegu, Republic of Korea and ${ }^{2}$ Department of Orthopedic Surgery, Kyungpook National University School of Medicine, Daegu, Republic of Korea

Correspondence: Dr K-S Jeong, DVM, PhD, Department of Pathology, College of Veterinary Medicine, Kyungpook National University, 702-701, \#1370 Sangyeok-dong, Buk-ku, Daegu, Republic of Korea.

E-mail: jeongks@knu.ac.kr

Received 9 January 2010; revised 25 March 2010; accepted 19 April 2010
} 
patients with HCC. ${ }^{18,19} H$. hepaticus, a newly recognized Helicobacter sp., was experimentally proven to cause chronic hepatitis and HCC in mice. ${ }^{20}$ These all suggest that $H$. pylori may contribute to the development of liver diseases. However, there has been controversy on whether or not $H$. pylori could have a role in the development of cirrhosis and HCC. $^{21}$ For this reason, the possible role of $H$. pylori in the progression of liver diseases remains to be determined. Meanwhile, our recent study supports a possible implication of H. pylori in the pathogenesis of hepatic fibrosis and cirrhosis by showing that $H$. pylori significantly accelerated the $\mathrm{CCl}_{4}$-induced hepatic fibrosis in both rats and mice models. ${ }^{22}$ The recognition of $H$. pylori as a possible risk factor for fastidious liver diseases such as cirrhosis and HCC might have a practical impact on the therapy for them, by treatment of the infection and not liver transplantation or any longterm management. A recent outstanding study showed that bacterial lipopolysaccharide (LPS) intoxication promoted hepatic fibrosis by enhancing the transforming growth factorbeta1 (TGF- $\beta 1$ ) signaling through a toll-like receptor 4 (TLR4)-myeloid differentiation primary response gene 88 (MyD88)-nuclear factor kappa-light-chain enhancer of activated B cells (NF- $\kappa \mathrm{B})$ axis in HSCs, which provides a novel link between pro-inflammatory and pro-fibrogenic signals. ${ }^{23}$ Herein, we hypothesized that $H$. pylori accelerates hepatic fibrosis through the enhancement of inflammatory signaling. Therefore, we investigated this possibility by examining the effects of $H$. pylori on the expressions of various factors that are relevant to fibrosis and inflammation, such as mitogenactivated protein (MAP) kinases, TGF- $\beta 1$, and inflammatory cytokines. Thereby, additional manifestations supporting the involvement of $H$. pylori in the pathogenesis of liver diseases are presented.

\section{MATERIALS AND METHODS Bacterial Strains}

H. pylori ATCC 43504 (a cagA+, s1-m1 vacA type) were used. H. pylori was grown on Mueller Hinton (MH) agar supplemented with an antibiotic mixture and 5\% horse serum, and then incubated for $48 \mathrm{~h}$ at $37^{\circ} \mathrm{C}$ under microaerophilic conditions. The cells were harvested in phosphatebuffered saline (PBS), centrifuged at $5000 \mathrm{~g}$ for $10 \mathrm{~min}$, and resuspended in PBS. The cell suspension was subjected to an ultrasonic standing wave field, for 5 cycles, each of 1-min duration followed by centrifugation $(10000 \mathrm{~g}$ for $10 \mathrm{~min}$, $4{ }^{\circ} \mathrm{C}$ ). The resulting supernatant was then filtered with a $0.22-\mu \mathrm{m}$ syringe filter and used for $H$. pylori lysates.

\section{Rat Hepatic Stellate Cell (HSC) Cell Line Culture}

The rat HSC Cell line HSC-T6 ${ }^{24}$ was cultured in minimal essential medium (MEM) supplemented with $10 \%$ fetal bovine serum (FBS) and $1 \%$ penicillin-streptomycin at $37^{\circ} \mathrm{C}$ in a $5 \% \mathrm{CO}_{2}$ incubator.

\section{Sample Collections}

To elucidate the mechanism by which $H$. pylori accelerate hepatic fibrosis, the same liver samples that were described in an earlier paper ${ }^{22}$ were used in this study. Animal procedures were conducted in accordance with the NIH guidelines. Briefly, the study design and protocol was as follows: 8 -weeks-old female C57BL/6 mice ( $n=32, n=8$ per group) were divided into four groups: normal control group, H. pylori-infected group, $\mathrm{CCl}_{4}$-treatment group, and H. pylori $+\mathrm{CCl}_{4}$ treatment group. Mice were injected intraperitoneally with $10 \% \mathrm{CCl}_{4}$ dissolved in olive oil, or olive oil alone $(1.0 \mathrm{ml} / \mathrm{kg}$ body weight), coupled with orogastric inoculation of $H$. pylori containing $10^{9} \mathrm{CFU} / \mathrm{ml}$ or an equal volume of phosphate-buffered saline (PBS) three times a week for 15 weeks. Sixteen weeks after the start of experiment, the animals were fasted overnight. Blood was collected under diethyl ether anesthesia, and then the animals were euthanized. The liver samples were obtained from multiple lobes followed by either being fixed in $10 \%$ neutralbuffered formalin, or being minced and quick-frozen by immersion into liquid nitrogen.

\section{Biochemical Measurement}

The serum levels of tumor necrosis factor-alpha (TNF- $\alpha$ ) and TGF- $\beta_{1}$ were determined by means of commercially available kits (R \& D system, Minneapolis, MN, USA).

\section{Histopathology and Immunohistochemistry}

Formalin-fixed paraffin-embedded sections of liver samples were cut into $4 \mu \mathrm{m}$ thicknesses and proliferating cell nuclear antigen (PCNA) immunostaining on the liver section was performed using the monoclonal mouse antibody against PCNA (Santa Cruz Biotechnology, Santa Cruz, CA, USA). The antigen-antibody complex was visualized with avidinbiotin-peroxidase complex $(\mathrm{ABC})$ immunostaining (Vector Laboratories, Burlingame, CA, USA) by 3,3-diaminobenzidine (Zymed Laboratories, San Francisco, CA, USA). The sections were then counterstained with Mayer's hematoxylin or methyl green. A quantitative analysis of apoptosis was performed using a commercial kit for TUNEL (Apop Tag kit, S7100, Chemicon, CA, USA), according to the manufacturer's protocols.

\section{Biochemical Measurements}

Frozen liver fragments were homogenized in RIPA buffer (150 mM NaCl, $50 \mathrm{mM}$ Tris-HCl, pH 7.4, $5 \mathrm{mM}$ EDTA, 1\% Nonidet P-40, 0.5\% deoxycholate, and 0.1\% SDS) containing $0.1 \mathrm{mM}$ sodium orthovanadate and protease inhibitor $(40 \mathrm{mg}$ liver per $1 \mathrm{ml}$ lysis buffer) by grinding the tissue into a fine powder with liquid nitrogen in a pre-chilled mortar and pestle followed by centrifugation at $10000 \mathrm{~g}$ for $20 \mathrm{~min}$. The resulting supernatants, without the lipid layer, were added to each assay mixture. 


\section{Immunoblot Analysis of Liver Homogenates}

Whole liver protein homogenates $(40 \mu \mathrm{g})$ were subjected to sodium dodecyl sulfate-polyacrylamide gel electrophoresis (SDS-PAGE) and transferred to Immobilon-P membranes (Millipore, Billerica, MA, USA). The membranes were incubated with various antibodies; anti-extracellular signalregulated kinase (ERK), anti-c-Jun N-terminal kinase (JNK), anti-p38, anti-p53, anti-p21, anti-Bax, anti-PCNA, antiactivator protein 1 (AP-1), and anti-NF- $\kappa \mathrm{B}$ inhibitor alpha $(\mathrm{I} \kappa \mathrm{B} \alpha)$ (Santa Cruz Biotechnology, Santa Cruz, CA, USA, 1:200); anti-Cu/Zn-superoxide dismutase (SOD1) and antiglutathione peroxidase (GPx) (Assay Designs, Ann Arbor, MI, USA, 1:500); monoclonal anti-pERK, anti-pp38, antipJNK1/2; anti-pp53 (ser-15) (Cell Signaling Technology, Danvers, MA, USA, 1:200); anti- $\beta$-tubulin (Sigma-Aldrich, St Louis, MO, USA, 1:1000).

\section{RNA Extraction and Reverse Transcriptase (RT)-PCR}

Total RNAs were extracted from frozen liver tissues using Trizol (Invitrogen, Carlsbad, CA, USA) according to the manufacturer's instructions. Briefly, frozen liver fragments were homogenized in $1 \mathrm{ml}$ of Trizol by grinding the tissue into a fine powder with liquid nitrogen in a pre-chilled mortar and pestle followed by centrifugation at $10000 \mathrm{~g}$ for $20 \mathrm{~min}$. Total RNA from the resulting supernatants was separated from protein and DNA by extraction with chloroform and then precipitated with isopropanol. The RNA pellet following washing in 75\% alcohol was dissolved in diethylene-pyrocarbonate (DEPC)-treated water. The concentration of RNA was quantified with a Quant-iT RNA assay kit using the Qubit fluorometer (Invitrogen). In all, $100 \mathrm{ng}$ of total liver RNA was used to prepare the cDNA using a random octamer and RT \& GO mastermix (MP Biomedicals, Solon, OH, USA) or 1-step AccuPower RT-PCR premix (Bioneer, Daejeon, South Korea) according to the manufacturer's instructions. The forward and reverse primers used are shown in Supplementary Table S1. The cDNA was amplified by 40 cycles consisting of $30 \mathrm{~s}$ at $94^{\circ} \mathrm{C}, 30 \mathrm{~s}$ at $48-50^{\circ} \mathrm{C}$ and $30 \mathrm{~s}$ at $72^{\circ} \mathrm{C}$ followed by a single terminal extension at $72^{\circ} \mathrm{C}$ for $10 \mathrm{~min}$. In all, $5-10 \mu \mathrm{l}$ of amplification product was recovered by performing $1.5 \%$ agarose gel electrophoresis.

\section{Cell Proliferation}

Cell proliferation was determined by 3-(4,5-dimethylthiazol2-yl)-2,5-diphenyltetrazolium bromide (MTT) assay (Roche, Mannheim, Germany), according to the manufacturer's protocols. Briefly, cells were seeded at $2 \times 10^{4}$ cells per well into 96-well plates and were grown overnight. The grown cells were washed with PBS and overlaid with a serum-free culture medium in the presence or absence of TGF- $\beta 1$ to which $H$. pylori lysates were added. After incubation for $12 \mathrm{~h}$, cell viability was determined.

\section{Statistics}

The cell proliferation rate was analyzed by ANOVA with post-hoc comparison of the means. The differences among the groups were compared by the Kruskal-Wallis test. The differences between the groups were compared by Student's $t$-test. Results are expressed as mean or median \pm standard error (s.e.) for data in each indicated treated group. $P<0.05$ was considered significant. All statistical analyses were performed using the SPSS 14.0 statistical software program.

\section{RESULTS \\ Association of $\boldsymbol{H}$. Pylori Infection with the Levels of TGF- $\beta 1$ and TNF- $\alpha$ in Sera}

According to the earlier study, ${ }^{22}$ obvious signs of hepatic fibrosis in $\mathrm{H}$. pylori plus $\mathrm{CCl}_{4}$ treatment group were observed compared with that in $\mathrm{CCl}_{4}$ treatment alone, whereas $H$. pylori treatment alone did not induce hepatic fibrosis; the grade of fibrosis seen in $\mathrm{H}$. pylori plus $\mathrm{CCl}_{4}$-treated mice increased by about $60 \%(P<0.01)$ as compared with that of $\mathrm{CCl}_{4}$-alone-treated mice and liver necrosis was augmented by twofold increases, based on serum AST/ALT levels $(P<0.05)$. In the study, another serum biochemical analysis was presented. The level of TNF- $\alpha$ was increased in both the H. pylori-treated groups $(P=0.038)$ (Figure 1a), indicating that it might be induced by $H$. pylori infection. Unexpectedly, serum TGF- $\beta 1$ level was the highest in the control group of all the experimental groups $(P=0.003)$ (Figure 1b). Except for the control group, there was a tendency for the more injured groups to have higher TGF- $\beta 1$ levels. Taken together, high TGF- $\beta 1$ along with elevated TNF- $\alpha$ may be associated with augmented hepatic fibrosis in the $H$. pylori plus $\mathrm{CCl}_{4}$-treated group.

\section{H. Pylori Increases $\mathrm{CCL}_{4}$-Induced MAP Kinase Signal Pathway}

As MAP kinases are activated in response to a wide variety of extracellular stimuli, ${ }^{25} \mathrm{H}$. pylori and/or $\mathrm{CCl}_{4}$-induced MAP kinases activation was investigated. JNK1 activation was induced by exogenous stimuli including $\mathrm{H}$. pylori and $\mathrm{CCl}_{4}$, and the levels of pJNK correlated with the extent and severity of liver damage and fibrosis (Figure 2). The activation of ERK and $\mathrm{p} 38$ were induced in $\mathrm{CCl}_{4}$-intoxicated livers, to which the inoculation of $H$. pylori further increased the phosphorylation of ERK and p38 (Figure 2).

\section{H. Pylori Augments mRNA Expressions of Proinflammatory Cytokines Induced by $\mathrm{CCL}_{4}$ Intoxication}

Fibrosis is a common response to hepatocellular necrosis or damage induced by inflammation. ${ }^{26}$ JNK1 signaling cascade is known to phosphorylate a number of downstream targets, including the transcription factors ATF-2, ELK-1, and c-Jun, with the latter being required for the regulation of inflammatory cytokine gene expression. ${ }^{27}$ ERK MAP kinase has been required in TGF- $\beta 1$-mediated NF $\kappa \mathrm{B}$ activation and 

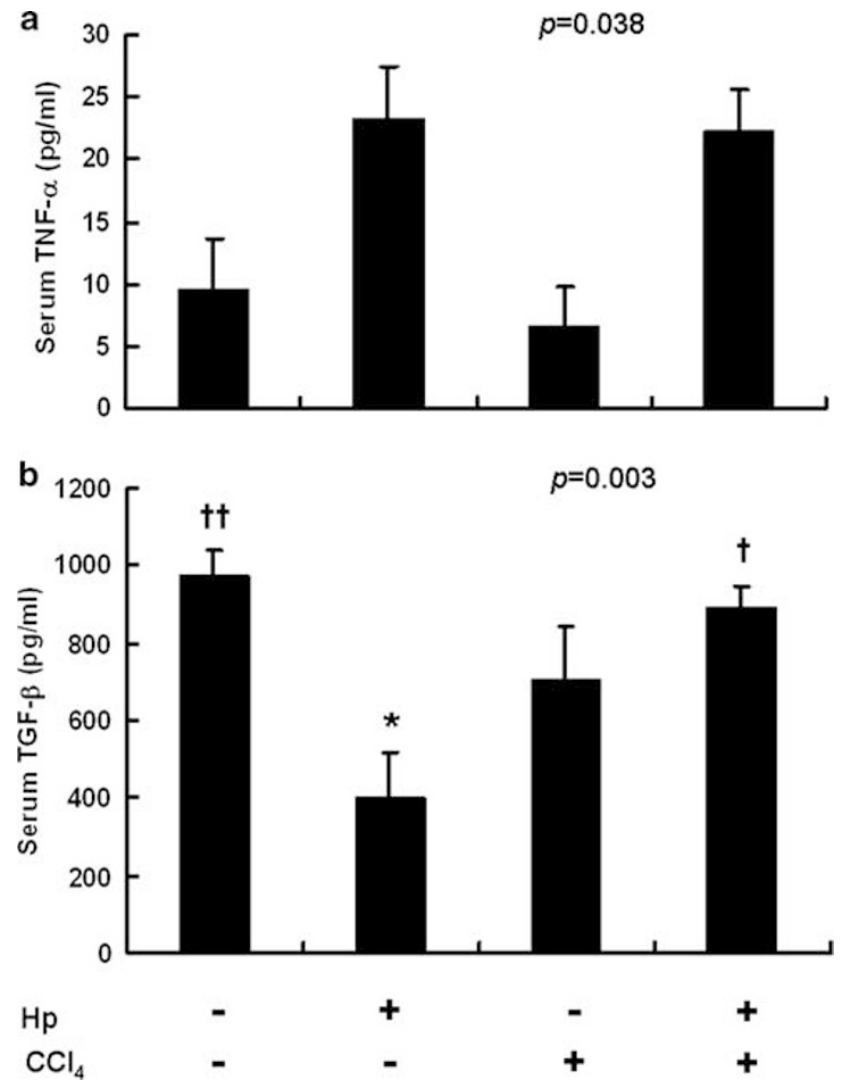

Figure 1 Serum levels of TGF- $\beta 1$ and TNF- $\alpha$ following $\mathrm{CCl}_{4}$ intoxication with or without $H$. pylori infection during 16 weeks. (a) Quantification of serum levels of TNF- $\alpha$ in experimental animals. There was a significant difference among groups by Kruskal-Wallis test $(P=0.038)$. (b) Quantification of serum levels of TGF- $\beta 1$ in experimental animals. There was a significant difference between groups analyzed by Kruskal-Wallis test $(P=0.003)$. Statistically significant as compared with control group $\left({ }^{*} P<0.01\right)$; statistically significant as compared with the $H$. pylori-treatment group $\left({ }^{\dagger} P<0.05,{ }^{\dagger} P<0.01\right)$.

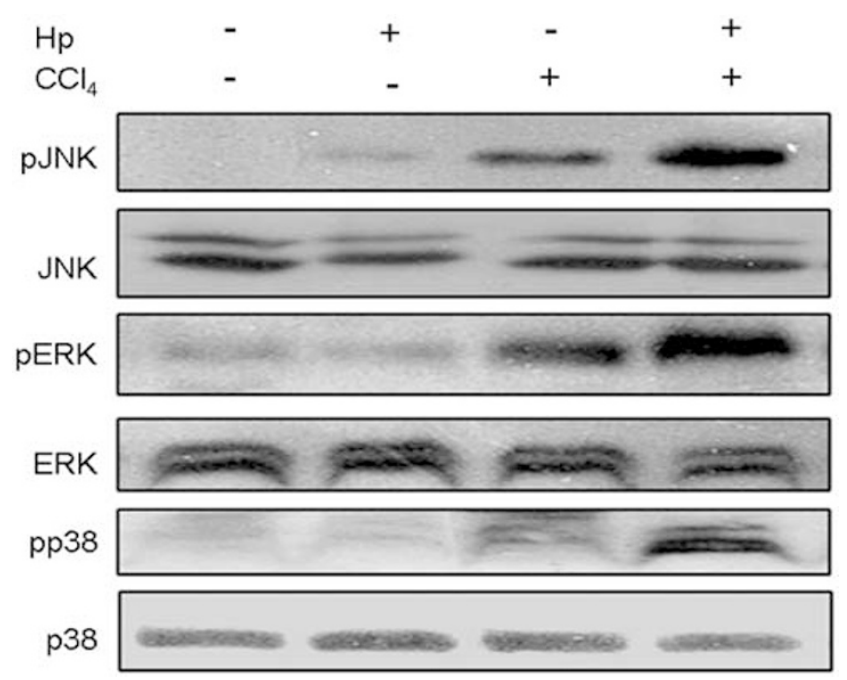

Figure 2 MAP kinases signaling in livers in response to $\mathrm{CCl}_{4}$ with or without $H$. pylori infection. Quantitative expression of representative of JNK, ERK, p38 and each one's own phosphorylated form in liver homogenates were determined by immunoblot analysis. Data are representative of at least two experiments.

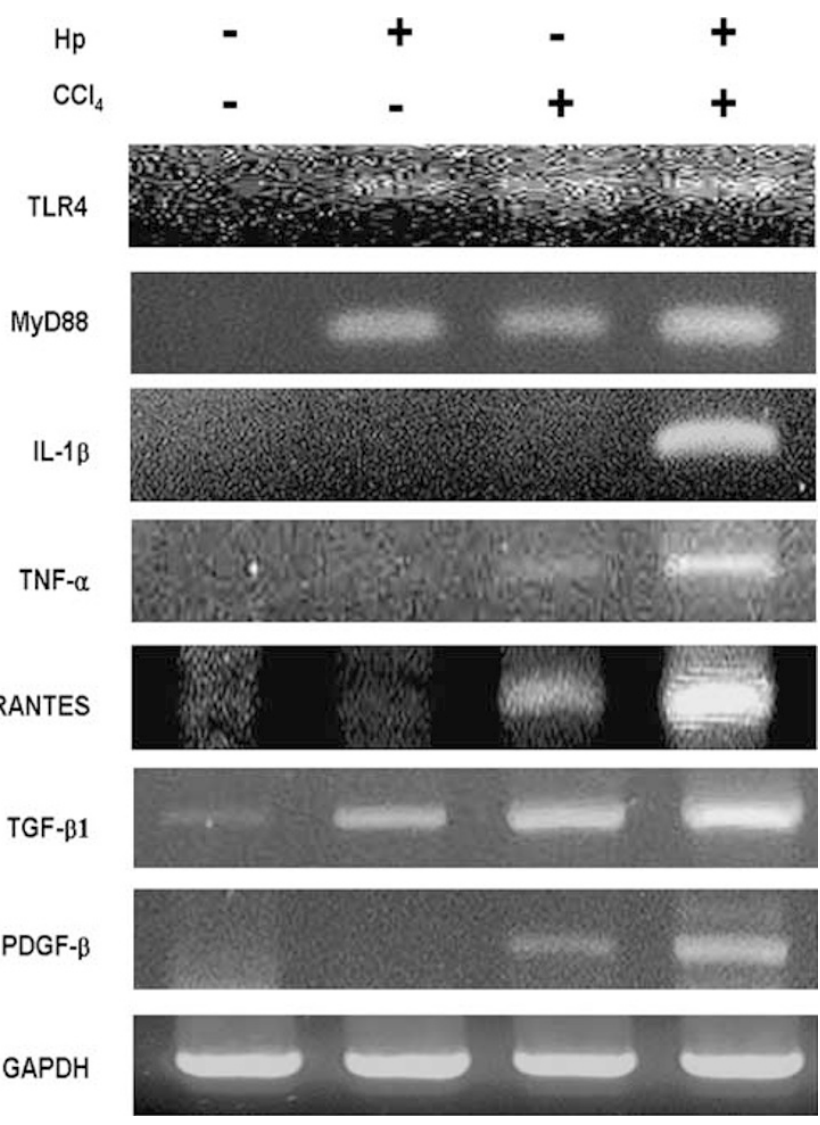

Figure 3 Expression of factors involved in inflammation and fibrogenesis. Expression of mRNA factors associated with pro-inflammatory and profibrotic cytokines were analyzed by RT-PCR. The expressions of GAPDH mRNA are shown as control for relative quantitation of gene expression. Data are representative of at least two experiments.

transcriptional autoinduction of TGF- $\beta .^{28}$ Therefore, having confirmed activation of both JNK and ERK MAP kinase pathways on stimulation from $\mathrm{CCl}_{4}$ and/or $\mathrm{H}$. pylori in the liver, the results of the downstream of those MAP kinases, namely the expressions of inflammatory cytokines, were examined. As shown in Figure 3, mRNAs of IL- $\beta 1$, TNF- $\alpha$, and RANTES were definitely expressed in livers of the $H$. pylori plus $\mathrm{CCl}_{4}$-treated group. The expression levels of profibrotic factors, such as TGF- $\beta 1$ and PDGF- $\beta$, were high in livers of the $H$. pylori and $\mathrm{CCl}_{4}$-treated group in comparison with those of the $\mathrm{CCl}_{4}$-alone treatment group. TLR4 has an essential role in the activation of innate immunity by recognizing that lipopolysaccharide (LPS) and MyD88, an intracytoplasmic adapter, are essential for the induction of inflammatory cytokines triggered by all TLRs. ${ }^{29}$ The expression of TLR4, an upstream of MAP kinase signaling, was induced in livers of the $\mathrm{H}$. pylori or/and $\mathrm{CCl}_{4}$-treated mice; the expression of MyD88, another upstream of MAP kinases, was coincident with the expressions of TLR4. Although both $H$. pylori and $\mathrm{CCl}_{4}$ alone appeared to induce TLR4/MyD88 signaling pathways, $H$. pylori plus $\mathrm{CCl}_{4}$ treatment was found 
most likely to activate this signaling, based on the increased expressions of inflammatory cytokines.

\section{H. Pylori Modulates Oxidative Stress}

$\mathrm{CCl}_{4}$-induced oxidative stress contributes to liver damage and inflammation that, in turn, causes hepatic fibrosis. MAP kinase activation is also linked to the development of cell injury by $H$. pylori-induced oxidative stress as well. ${ }^{30}$ Concordant with hepatic fibrosis, the hepatic levels of SOD1, a specific scavenger of superoxide anion, were decreased in the livers of $\mathrm{CCl}_{4}$-intoxicated groups where $H$. pylori was not likely to affect the reduction of SOD1 levels (Figure 4a and b). Catalase (CAT) and GPx, two $\mathrm{H}_{2} \mathrm{O}_{2}$-scavenging enzymes, remained virtually unchanged upon $\mathrm{CCl}_{4}$-induced oxidative stress as compared with those of the control group, whereas the $H$. pylori treatment increased those levels; especially, the GPx level was clearly increased in livers of the H. pylori plus $\mathrm{CCl}_{4}$ treatment group (Figure 4a and c). A sudden increase in GPx expression may be associated with increased production of reactive oxygen species (ROS) such as $\mathrm{H}_{2} \mathrm{O}_{2}$, based on the more severe hepatic fibrosis and inflammation in livers of the $\mathrm{H}$. pylori plus $\mathrm{CCl}_{4}$-treated group and increased CAT expressions in livers of both H. pylori-treated groups (Figure $4 \mathrm{a}$ and $\mathrm{d}$ ).

\section{H. Pylori Upregulates $\mathrm{CCL}_{4}$-Induced Proliferation and Growth Arrest}

Activation of MAP kinases has also been linked in specific cell types to apoptotic and necrotic injury, growth arrest, and proliferation. ${ }^{31}$ Hepatic p53 expression was increased in the $H$. pylori treatment group as well as the $\mathrm{CCl}_{4}$-intoxicated groups (Figure 5a). The p21 expression was significantly increased in the $H$. pylori plus $\mathrm{CCl}_{4}$-intoxicated group, in accordance with the phosphorylation on serine 15 of p53 (Figure 5a). Maintaining cells in the G1 phase by p53-mediated p21 protects cells from replicating damaged DNA and facilitates DNA repair. ${ }^{32}$ If p21-induced growth arrest persists, the regenerative capacity (or proliferation) will decline, causing cellular senescence and apoptosis. Conversely, the expression of PCNA and proliferative index (PI) of hepatocytes were significantly increased in livers of the $\mathrm{H}$. pylori plus $\mathrm{CCl}_{4}$ treatment mice, as compared with those of $\mathrm{CCl}_{4}$-alone treatment mice, whereas there were no significant difference in Bax expression and the apoptotic index (AI) of hepatocytes between the $\mathrm{CCl}_{4}$-treated and $\mathrm{H}$. pylori plus $\mathrm{CCl}_{4}$-treated groups (Figure $5 \mathrm{~b}$ and c). Therefore, an increase in p21 might be caused by an increase in hepatocyte proliferation in livers of the $H$. pylori plus $\mathrm{CCl}_{4}$-treated mice.

In order to confirm whether or not increased proliferation in liver sections of the $H$. pylori plus $\mathrm{CCl}_{4}$ might be associated with the occurrence of liver cancer, the expressions of AFP, a diagnostic marker of HCC, on liver sections were investigated (Supplementary Figure S1). There were a less number of AFP-positive hepatocytes found in control and $\mathrm{CCl}_{4}$-alonetreated livers. However, a higher level of AFP expression was found in liver sections of the H. pylori alone and the H. pylori plus $\mathrm{CCl}_{4}$-treated mice than in those of $\mathrm{CCl}_{4}$-alone-treated mice, indicating that $H$. pylori infection may have a role in the AFP expression in hepatocytes.
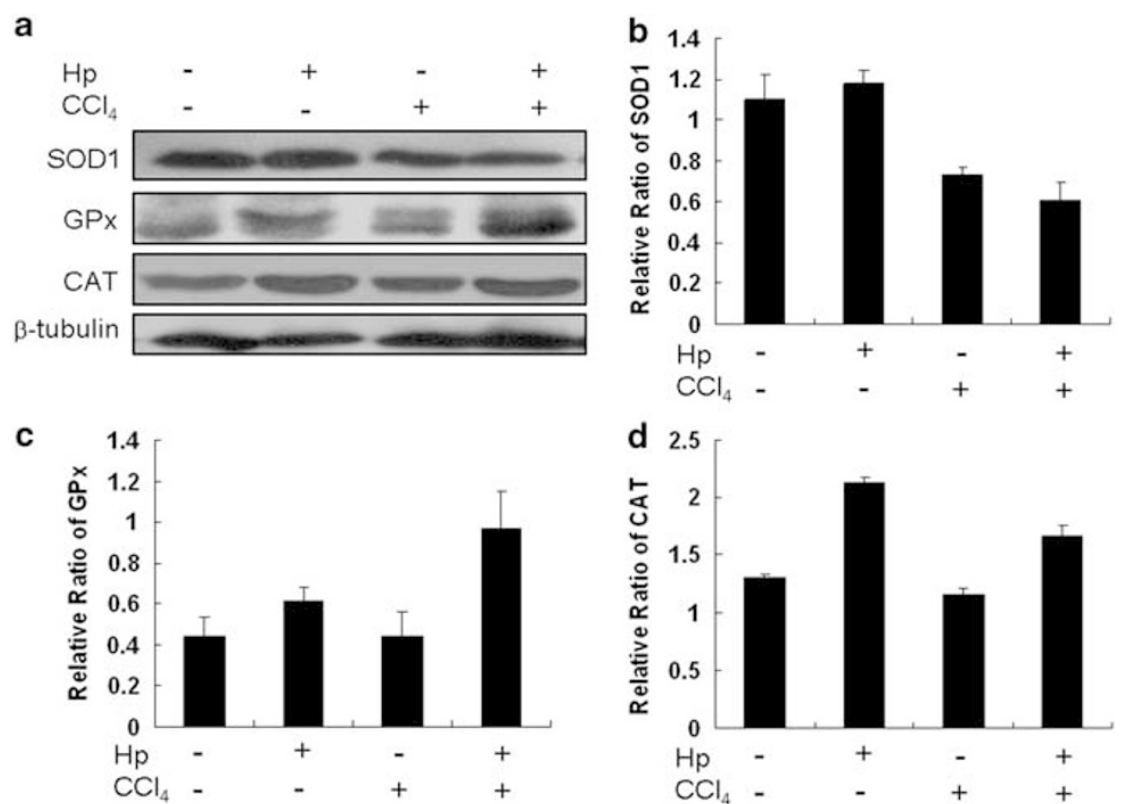

Figure 4 Differential expression of SOD1, GPx, and CAT in injured livers. (a) The expressions of representative of SOD1, GPx or CAT were determined by immunoblotting in liver homogenates of experimental groups. The expressions of $\beta$-tubulin are shown as loading controls. (b-d) Relative ratio of SOD1, GPx or CAT to $\beta$-tubulin was measured with Image J software. Data are representative of at least two experiments. Values are mean \pm s.d. 

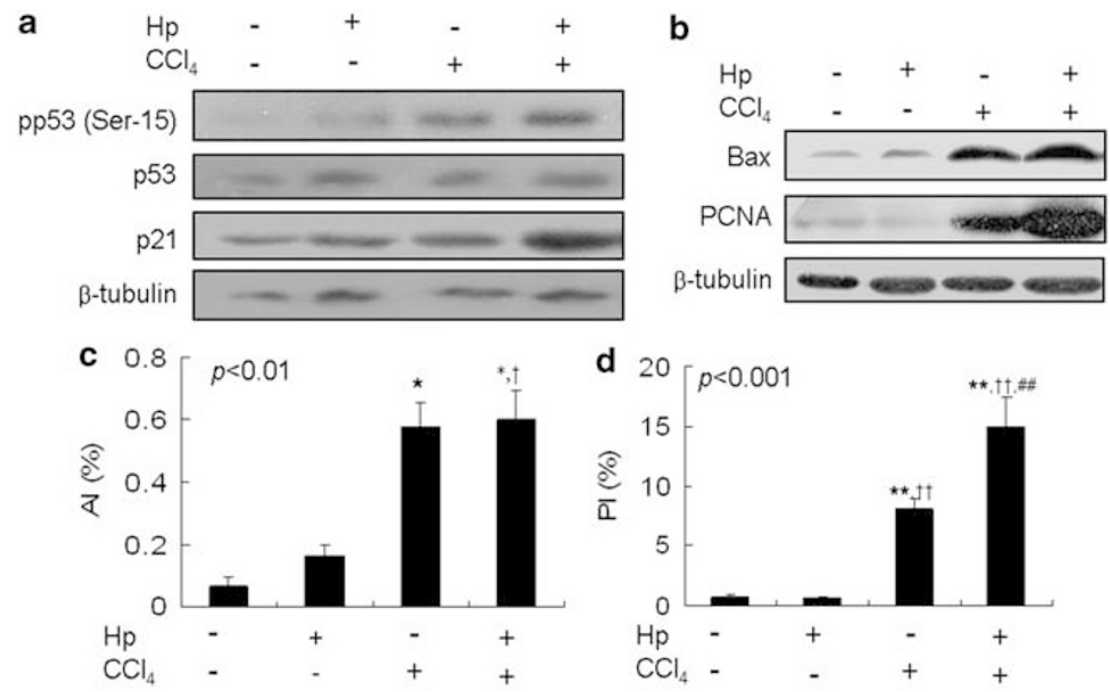

Figure 5 Effect of $H$. pylori on apoptosis and proliferation of hepatocytes. (a) Hepatic expressions of p53, phopho-p53 (Ser-15), p21, and $\beta$-tubulin were determined by immunoblot analysis. The expressions of $\beta$-tubulin are shown as loading control. (b) Hepatic expressions of Bax and PCNA were determined by immunoblot analysis. Data are representative of at least two experiments. (c) Apoptotic index (Al) was expressed as percentage of positively stained cells with TUNEL method per 1000 hepatocytes per slide at magnification of $\times 100$. (d) Liver sections of slides were examined by immunohistochemical staining with anti-PCNA antibodies as a primary antibody. Proliferative index (PI) was expressed as percentage of positively stained cells per 1000 hepatocytes per slide at magnification of $\times 100$. All values are expressed as mean \pm s.e. of three mice per group. Statistically significant as compared with control group $\left({ }^{\star} P<0.05,{ }^{*} P<0.01\right)$; statistically significant as compared with $H$. pylori-treatment group $\left({ }^{\dagger} P<0.05,{ }^{\dagger} P<0.01\right)$; statistically significant as compared with $\mathrm{CCl}_{4}$-treatment group, ${ }^{\# \#} P<0.01$ ).

a

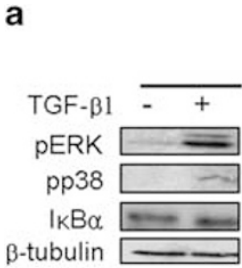

C

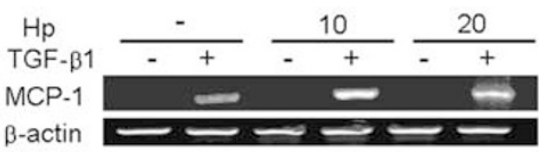

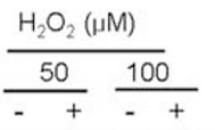
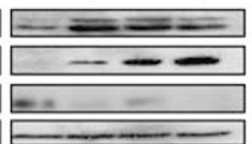
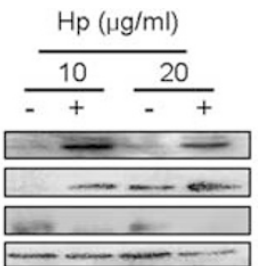

b

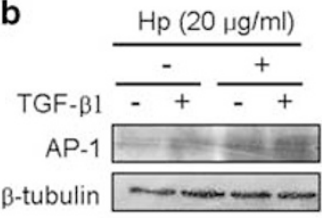

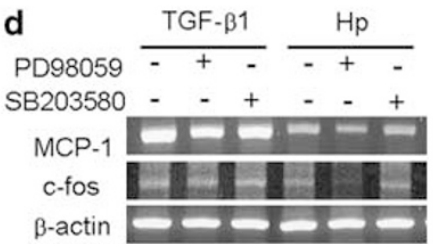

Figure 6 Effect of $\mathrm{H}_{2} \mathrm{O}_{2}$ or $H$. pylori lysates on the activation of MAPKs and the reduction of $\mathrm{I}_{\kappa} \mathrm{B} \alpha$ in cultured rat HSCs with and without TGF- $\beta 1$ exposure. (a) $\mathrm{HSCs}$ were co-cultured with or without the indicated $\mathrm{H}_{2} \mathrm{O}_{2}$ or $\mathrm{H}$. pylori lysates in the presence or absence of $50 \mathrm{pg} / \mathrm{ml}$ of TGF- $\beta 1$ in a serum-free medium. After a 2-h incubation period, HSCs were washed in PBS and then lysed with $2 \times$ SDS sample buffer. The lysed cells were assessed for phosphorylated ERK $1 / 2, \mathrm{p} 38$, and $\mathrm{I}_{\kappa} \mathrm{B} \alpha$ by an immunoblotting. The expression of $\beta$-tubulin are shown as loading controls. (b) $\mathrm{HSCs}$ were exposed to $20 \mu \mathrm{g} / \mathrm{ml}$ of $\mathrm{H}$. pylori lysates in the presence or absence of $50 \mathrm{pg} / \mathrm{ml}$ of TGF- $\beta 1$. The lysed cells were assessed for AP-1 by immunoblotting. (c) Expression of MCP-1 mRNA was analyzed by RT-PCR. (d) Expression of MCP-1 or c-fos mRNA with or without either PD98059 or SB203580 was analyzed by RT-PCR in HSCs exposed to $50 \mathrm{pg} / \mathrm{ml}$ of TGF- $\beta 1$ or $40 \mu \mathrm{g} / \mathrm{ml}$ of $H$. pylori lysates for $2 \mathrm{~h}$. The expressions of $\beta$-actin mRNA are shown as control for relative quantitation of gene expression. Data are representative of at least two experiments.

\section{H. Pylori Lysates Elevate TGF- $\beta 1$-Induced I $\kappa B \alpha$ Degradation}

To investigate the role of $H$. pylori in liver fibrogenesis, the effect of $H$. pylori lysates in the absence or presence of TGF- $\beta 1$ on immortalized rat HSCs was examined. TGF- $\beta 1$-induced activation of MAP kinases has been required for HSC activation. ${ }^{33}$ As shown in Figure $6 \mathrm{~b}$, TGF- $\beta 1$ activated ERK and p38 MAP kinases in HSCs. Moreover, TGF- $\beta 1$ stimulated MAP kinase activation was hastened in the presence of $10 \mu \mathrm{g} / \mathrm{ml}$ of $\mathrm{H}$. pylori lysates or $50 \mu \mathrm{M}$ of $\mathrm{H}_{2} \mathrm{O}_{2}$. This might be increased by $\mathrm{H}$. pylori infection based on the results shown in Figure 4. At higher concentration of $\mathrm{H}_{2} \mathrm{O}_{2}$ 
$(100 \mu \mathrm{M})$ or $H$. pylori lysates $(20 \mu \mathrm{g} / \mathrm{ml})$ along with TGF- $\beta 1$, the level of pERK was decreased, whereas that of pp38 was increased (Figure 6a). The degradation of $\mathrm{I} \kappa \mathrm{B} \alpha$ in cytoplasm is prerequisite for NF- $\kappa \mathrm{B}$ activation, resulting in the stimulation of a variety of pro-inflammatory target genes. ${ }^{34} \mathrm{I} \kappa \mathrm{B} \alpha$ reduction was definitely increased in the presence of both TGF- $\beta 1$ and $\mathrm{H}_{2} \mathrm{O}_{2}$ or $H$. pylori lysates than in the presence of either singly (Figure 6a). Another inflammatory signal mediated by AP- 1 was also induced not only by TGF- $\beta 1$ but also by $H$. pylori (Figure 6b). AP-1, a heterodimeric protein composed of c-Fos and c-Jun proteins, is an inducible transcriptional complex that is essential for cell adaptation to many environmental changes, resulting in a wide range of cellular processes such as inflammation, stress response, cell differentiation, and tumorigenesis. ${ }^{35}$ TGF- $\beta 1$ was required for the induction of MCP-1 expression in HSCs and the exposure of activated HSCs to $H$. pylori lysates potentiated the expression (Figure 6c). Whereas MCP-1 mRNA expressions were partially inhibited in TGF- $\beta 1$ treated HSCs by the addition of ERK MAP kinase inhibitor (PD98059), it was discernibly suppressed with $40 \mu \mathrm{g} / \mathrm{ml}$ of H. pylori-treated HSCs. Furthermore, c-fos mRNA was definitely downregulated by PD98059 in H. pylori-treated HSCs (Figure 6d). There were no discernible differences in MCP-1 or c-fos expression between the presence and absence of p38 MAP kinase inhibitor (SB203580).

\section{TGF- $\beta 1$ Induces ERK-Mediated HSCs Activation}

The proliferation of HSCs (HSC-T6) was assessed by MTT assay. The HSC proliferation rate was increased at $40 \mu \mathrm{g} / \mathrm{ml}$ of $H$. pylori lysates in a dose-dependent manner and decreased thereafter in the absence of TGF- $\beta 1$; however, the proliferation rate was increased at $20 \mu \mathrm{g} / \mathrm{ml}$ of $H$. pylori and declined thereafter in the presence of $50 \mathrm{pg} / \mathrm{ml}$ of TGF- $\beta 1$ (Figure 7a). TGF- $\beta 1$ significantly augmented HSCs proliferation by above $20 \%$ in the absence of $H$. pylori lysates and by above $60 \%$ in the presence of $20 \mu \mathrm{g} / \mathrm{ml}$ of $H$. pylori lysates (Figure 7a). H. pylori lysates stimulated HSC proliferation at lower concentration, whereas it stimulated cell apoptosis at higher concentration, and the apoptosis was more aggravated in the presence of TGF- $\beta 1$. As shown in Figure 6a, a decrease in pERK and an increase in pp38 levels at higher concentration of $\mathrm{H}_{2} \mathrm{O}_{2}(100 \mu \mathrm{M})$ or $H$. pylori lysates $(20 \mu \mathrm{g} / \mathrm{ml})$ along with TGF- $\beta 1$ may be associated with a decrease in HSC proliferation at those concentrations (Figure 7a). As for control, human hepatoma cell line Hep3B revealed decreased cell viability in the presence of TGF- $\beta 1$; in combination with H. pylori lysates, cell viability increased to less than $20 \%$ (Supplementary Figure S2). TGF- $\beta 1$-induced Hep3B cell death appeared to be mediated by p38 MAP kinase (Supplementary Figure S3). Both PD98059 and SB203580 suppressed TGF- $\beta 1$-induced HSC proliferation (Figure 7b); the former in particular had an especially stronger inhibitory
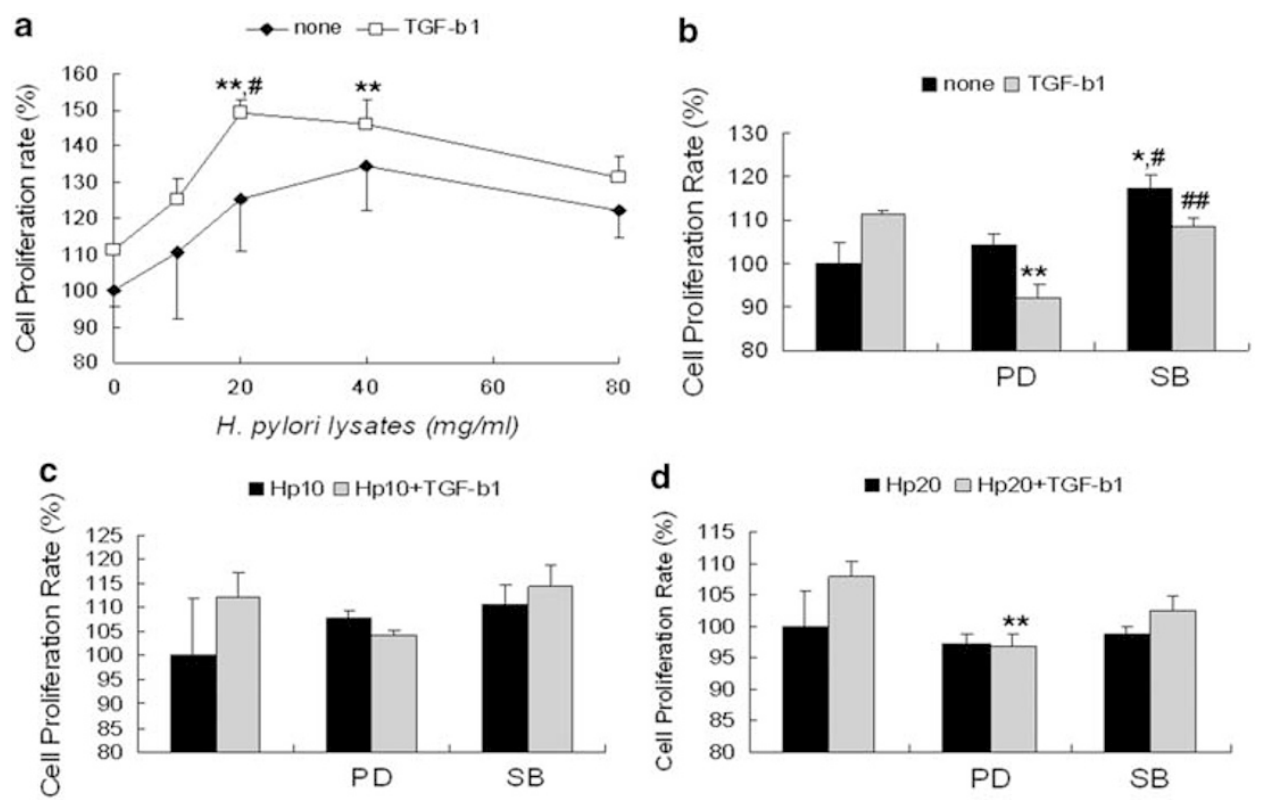

Figure 7 Effect of $H$. pylori lysates in the absence or presence of TGF- $\beta 1$ on the proliferation of HSC. Subconfluent HSC cells were treated with serum-free

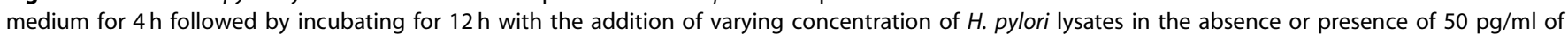
TGF- $\beta 1$. The cell proliferation rate depending on dose of $H$. pylori lysates (a) was measured by an MT cell proliferation colorimetric assay. The cells proliferation rate represents a percentage of the values of cells without both $H$. pylori lysates and TGF- $\beta 1$. The effect of either PD98059 or SB203580 on TGF- $\beta 1$-induced HSC proliferation rate (b), TGF- $\beta 1$ and $H$. pylori lysate $10 \mu \mathrm{g} / \mathrm{ml}$ (c) or $H$. pylori lysate $20 \mu \mathrm{g} / \mathrm{ml}$ (d) was determined by an MTT assay. The cell proliferation rate represents a percentage of the values of cells with neither TGF- $\beta 1$ nor any MAP kinase inhibitor (b-d) and the means and s.d. from triplet

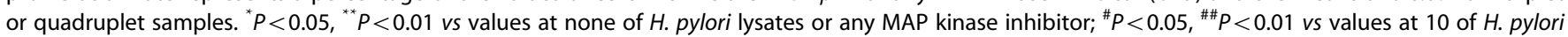
lysates or values in the presence of PD98059. 
effect against the HSC proliferation in the presence of TGF- $\beta 1$ plus $H$. pylori lysates than the latter (Figure $7 \mathrm{c}$ and $\mathrm{d}$ ). PD98059 inhibited $H$. pylori lysates-induced HSC proliferation at the partially high dose of $20 \mu \mathrm{g} / \mathrm{ml}$ of H.pylori lysates (Figure 7d).

\section{DISCUSSION}

There has been a trend for many patients with hepatic cirrhosis to have peptic ulcer of which the major causative agent is $H$. pylori. ${ }^{14-16}$ However, the pathological role of chronic $H$. pylori infection in liver diseases remains controversial. Our earlier report showed that $H$. pylori promotes hepatic fibrosis in rat and mouse models, in which Goo et $a l^{22}$ showed that $H$. pylori infection for 4-months duration caused functional and morphological degenerative changes in hepatocytes with slight focal necrotic and inflammatory changes, in spite of there being no severe hepatitis present. These changes in H. pylori-infected livers could provide a synergistic combination of liver damage when exposed to additional harmful stimuli. ${ }^{36}$ According to Abdel-Hady et al, ${ }^{37}$ a significant increase in fasting arterial blood ammonia and plasma endotoxin measurements was associated with $H$. pylori infection in cirrhotic patients and medical treatment of $H$. pylori infection led to a significant decrease in the severity of hepatic encephalopathy (HE) and fasting arterial blood ammonia levels. This evidence suggests that $H$. pylori infection might have a role in increasing the circulating levels of ammonia and endotoxins of cirrhotic patients, thus facilitating the onset of HE. Endotoxins such as LPS, have been known to cause hepatic inflammation by stimulating the secretion of a number of pro-inflammatory cytokines in liver diseases. ${ }^{38}$ The bacterial products can stimulate Kupffer cells to secrete reactive oxygen species and some cytokines such as TNF- $\alpha$ and TGF- $\beta 1$ to activate HSC, the main mediator of hepatic fibrosis. ${ }^{23}$ Serum TNF- $\alpha$ levels were increased in $H$. pylori treated groups, implying $H$. pylori increased systemic inflammation whereas serum TGF- $\beta 1$ levels were increased in $\mathrm{CCl}_{4}$-intoxicated mice except in control group. Hepatic fibrosis occurred only in $\mathrm{CCl}_{4}$-treated groups, indicating that $\mathrm{CCl}_{4}$-induced TGF- $\beta 1$ rather than $H$. pylori-induced TNF- $\alpha$ is the main cause of fibrogenesis; however, $H$. pylori-stimulated TNF- $\alpha$ may sensitize the liver to TGF- $\beta 1$-induced signals in $H$. pylori plus $\mathrm{CCl}_{4}$ treated group, resulting in aggravation of the $\mathrm{CCl}_{4}$-induced fibrosis.

TGF- $\beta$ and PDGF is involved in the development of fibrosis by regulating the activation of HSCs through Smad2/ 3 -mediated signaling. ${ }^{39,40}$ Whereas the serum levels of TGF- $\beta 1$ in the control group were comparable to those of the $\mathrm{CCl}_{4}$-treated groups, there was neither liver injury nor fibrosis in the control group. In addition, pSmad translocation into the nucleus of hepatocytes or endothelial cells was lower than in the $\mathrm{CCl}_{4}$-treated groups (data not shown). Under normal conditions, without any stimuli, TGF- $\beta 1$ / p-Smad signaling may be downregulated either by serum latent TGF- $\beta 1$ or by lower levels of TGF- $\beta 1$ receptors, whereas upon injury such as oxidative stress, aging, inflammation and so on, the active TGF- $\beta 1$ and/or the expression of TGF- $\beta 1$ receptor may be increased, thereby causing pSmad signaling to accelerate in HSCs. ${ }^{41}$

MAP kinase activation in livers was associated with the extent of the liver injury and fibrosis. JNK has a role in $\mathrm{CCl}_{4}$-induced liver damage by stimulating the production of pro-inflammatory cytokines through AP- $1^{42}$ and/or NF- $\kappa \mathrm{B}^{43}$ and with its prolonged activation promotes cell death (necrosis and/or apoptosis) depending on cell type and stimulus and may have both pro- or anti-apoptotic effects in hepatocytes. ${ }^{44,45}$ Recently, JNK activity has been reported to be required for TGF- $\beta$, angiotensin II-, and PDGF-induced HSC activation and proliferation, ${ }^{46}$ and in other study, to switch HSC proliferation toward apoptosis in response to bile duct acid, coupled with critical amounts of ROS formation in quiescent HSC. ${ }^{47}$ Although we did not present data related to JNK signaling in HSCs, TGF- $\beta 1$ increased JNK activity as well, indicating that the JNK activity is required for HSCs proliferation. Especially, inhibition of the p38 pathway increased JNK phosphorylation but ERK inhibition did not. Therefore, p38 may regulate JNK activity and JNK-mediated HSC proliferation or apotosis, which remains to be determined. ERK MAP kinase has been required in TGF- $\beta 1$ mediated $\mathrm{NF} \kappa \mathrm{B}$ activation and transcriptional autoinduction of TGF- $\beta{ }^{28}$ TGF- $\beta 1$-induced activation of p38 MAP kinase also has been required for HSC activation. ${ }^{33}$ It was extrapolated that MAP kinase-mediated NF $\kappa \mathrm{B} / \mathrm{AP}-1$ activation might be increased in the $H$. pylori plus $\mathrm{CCl}_{4}$-treated group based on increased mRNA expression of TNF- $\alpha$, IL- $1 \beta$, RANTES, TGF- $\beta 1$, and PDGF- $\beta$, coupled with a corresponding increase of TLR4 and MyD88 expression. According to Seki et al, ${ }^{23}$ HSCs other than Kupffer cells are the primary targets that drive fibrogenesis in response to TLR4 ligands. Thus, we sought the response of HSCs on H. pylori lysates in vitro. Exposure of HSC to $H$. pylori lysates led to the degradation of $\mathrm{IkB} \alpha$ in the presence of TGF- $\beta 1$, indicating $H$. pylori lysates promoted TGF- $\beta 1 / \mathrm{NF} \kappa \mathrm{B}$-mediated inflammation in HSCs. H. pylori lysates alone did not induce sufficient inflammation of HSCs as much as TGF- $\beta 1$ did. However, $H$. pylori lysates increased the expression of chemokines such as MCP-1 through $\mathrm{NF} \kappa \mathrm{B}$ activation, along with ERK activation in TGF- $\beta 1$-activated HSCs. According to the work of Zhang et al, ${ }^{28}$ neither ERK MAP kinase inhibition nor inhibition of p38 MAP kinase had any effect on TGF- $\beta 1$ induced protein binding to the AP-1 probe, while inhibition of the ERK MAP kinase activation attenuated TGF- $\beta 1$ stimulated binding to the NF- $\kappa \mathrm{B}$ consensus probe, which may explain the reason why TGF- $\beta 1$-mediated inflammation was partially inhibited by MAP kinase inhibitors, although in our results the activation of ERK MAP kinases appeared to be required for TGF- $\beta 1$-induced HSCs inflammation and proliferation. The inflammation of HSCs affecting liver fibrosis was more likely to be mediated by $\mathrm{NF} \kappa \mathrm{B}$ signaling rather than by AP-1, because $H$. pylori alone induced AP-1 
expression but it could not induce liver fibrosis. However, H. pylori infection in the presence of activated HSCs or HSCs activation by $H$. pylori infection could promote hepatic inflammation by an increase in production of potent neutrophil chemoattractants such as MCP-1.

Oxidative stress is a major pathogenic factor in hepatic fibrosis. Hydrogen peroxide can cause NF- $\kappa \mathrm{B}$ activation alone or in combination with TGF- $\beta 1$ that may also activate HSCs, which in turn may amplify hepatic inflammation through release of inflammatory cytokines. Hepatic levels of catalase and GPx were increased in H. pylori-treated groups, indicating that $H$. pylori may lead to an increase in the hepatic levels of $\mathrm{H}_{2} \mathrm{O}_{2}$ from activated Kupffer cells. Activated Kupffer cells express NADPH oxidase, by which $\mathrm{H}_{2} \mathrm{O}_{2}$ is generated, causing the activation of the HSCs. ${ }^{48,49}$ Endotoxins have resulted in a marked up-regulation of SOD-1 and GPx in rat hepatic endothelial cells for which the elimination of ROS may occur, whereas it has resulted in constitutively present SOD-1 and lack of upregulated GPx in Kupffer cells, implying an elevated production of $\mathrm{H}_{2} \mathrm{O}_{2}$ for bacterial killing. ${ }^{50}$ This earlier report could probably explain the reason why there were significantly elevated GPx expression in liver homogenates from the H. pylori plus $\mathrm{CCl}_{4}$-treated mice. It is certainly possible that an increase in activated Kupffer cells or $\mathrm{H}_{2} \mathrm{O}_{2}$ by $H$. pylori will contribute to the activation of HSCs.

Increased proliferation and similar extent of apoptosis of hepatocytes in the $\mathrm{H}$. pylori plus $\mathrm{CCl}_{4}$-treated mice may give rise to an overall net gain in proliferation that will progress to liver regeneration or tumorigenesis in response to toxic insults. TGF- $\beta 1$-induced activation of p38 MAP kinase has been required for TGF- $\beta$-induced apoptosis and epithelialmesenchymal transition (EMT). ${ }^{51}$ During tumor progression, TGF- $\beta 1$ initially has a role as a tumor suppressor as it inhibits the growth of cells; however, at later stages of tumor progression, it contributes to the metastatic process by promoting EMT. ${ }^{52}$ This possibility is shown in Supplementary Figures S3 and S4, wherein TGF- $\beta 1$ increased Hep3B viability when accompanied by $H$. pylori lysates. AFP is normally expressed in fetal hepatic tissue and stem cell-derived hepatocyte-like cells, ${ }^{53,54}$ and neoplasia of the liver ${ }^{55}$ but is absent from adult tissue. On that score, AFP could be used as a diagnostic marker for hepatocyte differentiation or HCC. As $H$. pylori infection increased hepatic AFP expression level and $\mathrm{CCl}_{4}$ intoxication increased TGF- $\beta 1$ levels, both in serum and tissues, $H$. pylori chronic infection might contribute to HCC progression from $\mathrm{CCl}_{4}$-induced fibrosis or cirrhosis. ${ }^{17,56}$ Meanwhile, primary HSC was reported to differentiate into a hepatocyte-like cell that is round in structure and expresses AFP when treated with FGF4, HGF, bFGF, and IL-6. ${ }^{54}$ H.pylori-induced inflammatory cytokines might lead hematopoietic progenitor cells as well as liver progenitor cells to differentiate into hepatocytes following liver damage, or abnormal proliferation of stem cells, which remains to be determined.
In conclusion, the data suggest that $H$. pylori endotoxins transported in the portal vein to the liver by the $H$. pylori infection, coupled with liver injury by $\mathrm{CCl}_{4}$, may accelerate hepatic fibrosis through increasing TGF- $\beta 1$-inducing proinflammatory signaling mediated by ERK and NF- $\kappa \mathrm{B}$ in HSCs. Therefore, $H$. pylori eradication might be a reasonable approach to treat some patients with hepatic fibrosis or cirrhosis along with $H$. pylori infection.

Supplementary Information accompanies the paper on the Laboratory Investigation website (http://www.laboratoryinvestigation.org)

\section{ACKNOWLEDGEMENT}

This research was supported by a grant (CBM 31-B3003-01-01-00) from the Center for Biological Modulators of the 21st Century Frontier R\&D Program, the Ministry of Science and Technology, Republic of Korea.

\section{DISCLOSURE/CONFLICT OF INTEREST}

The authors declare no conflict of interest.

1. Williams MP, Pounder RE. Helicobacter pylori: from the benign to the malignant. Am J Gastroenterol 1999;94(11 Suppl):S11-S16.

2. Cave DR. Transmission and epidemiology of Helicobacter pylori. Am J Med 1996;100(5A):12S-18S.

3. Yamada T, Searle JG, Ahnen D, et al. NIH consensus development panel on Helicobacter pylori in peptic ulcer disease. J Am Med Assoc 1994;272:65-69.

4. International Agency for research on Cancer. Evaluation of carcinogenic risks to humans, schistosomes, liver flukes and Helicobacter pylori. IARC Monogr Eval Carcinog Risks Hum 1994;61: 177-240.

5. Uemura N, Okamoto S, Yamamoto $\mathrm{S}$, et al. Helicobacter pylori infection and the development of gastric cancer. N Engl J Med 2001;345: 784-789.

6. Houghton J, Wang TC. Helicobacter pylori and gastric cancer: a new paradigm for inflammation-associated epithelial cancers. Gastroenterology 2005;128:1567-1578.

7. Wotherspoon AC. Gastric lymphoma of mucosa-associated lymphoid tissue and Helicobacter pylori. Annu Rev Med 1998;49:289-299.

8. Stasi R, Sarpatwari A, Segal JB, et al. Effects of eradication of Helicobacter pylori infection in patients with immune thrombocytopenic purpura: a systematic review. Blood 2009;113:1231-1240.

9. Pietroiusti A, Diomedi M, Silvestrini $M$, et al. Cytotoxin-associated gene$A^{-}$-positive Helicobacter pylori strains are associated with atherosclerotic stroke. Circulation 2002;106:580-584.

10. Pradhan AD, Manson JE, Rifai N, et al. C-reactive protein, interleukin 6, and risk of developing type 2 diabetes mellitus. JAMA 2001;286: 327-334.

11. Oshima T, Ozono R, Yano $\mathrm{Y}$, et al. Association of Helicobacter pylori infection with systemic inflammation and endothelial dysfunction in healthy male subjects. J Am Coll Cardiol 2005;45:1219-1222.

12. Ki MR, Shin DG, Park JS, et al. Frequency of vacuolating cytotoxin A (VacA)-positive Helicobacter pylori seropositivity and TGF-beta(1) decrease in atrial fibrillation. Int J Cardiol 2009. doi:10.1016/ j.ijcard.2009.12.009 [e-pub ahead of print].

13. Imai J, Yamada T, Saito T, et al. Eradication of insulin resistance. Lancet 2009;374:264.

14. Ponzetto A, Pellicano R, Leone $\mathrm{N}$, et al. Helicobacter infection and cirrhosis in hepatitis $C$ virus carriage: is it an innocent bystander or a troublemaker? Med Hypoth 2000;54:275-277.

15. Rocha M, Avenaud P, Ménard A, et al. Association of Helicobacter species with hepatitis C cirrhosis with or without hepatocellular carcinoma. Gut 2005;54:396-401.

16. Ponzetto A, Pellicano R, Leone N, et al. Helicobacter pylori seroprevalence in cirrhotic patients with hepatitis $B$ virus infection. Neth J Med 2000;56:206-210. 
17. Leone N, Pellicano R, Brunello $\mathrm{F}$, et al. Helicobacter pylori seroprevalence in patients with cirrhosis of the liver and hepatocellular carcinoma. Cancer Detect Prev 2003;27:494-497.

18. Nilsson HO, Taneera J, Castedal M, et al. Identification of Helicobacter pylori and other Helicobacter species by PCR, hybridization, and partial DNA sequencing in human liver samples from patients with primary sclerosing cholangitis or primary biliary cirrhosis. J Clin Microbiol 2000;38:1072-1076.

19. Huang Y, Fan XG, Wang ZM, et al. Identification of helicobacter species in human liver samples from patients with primary hepatocellular carcinoma. J Clin Pathol 2004;57:1273-1277.

20. Ward JM, Fox JG, Anver MR, et al. Chronic active hepatitis and associated liver tumors in mice caused by a persistent bacterial infection with a novel Helicobacter species. J Natl Cancer Inst 1994;86:1222-1227.

21. Pellicano R, Ménard A, Rizzetto $M$, et al. Helicobacter species and liver diseases: association or causation? Lancet Infect Dis 2008;8: 254-260.

22. Goo MJ, Ki MR, Lee HR, et al. Helicobacter pylori Promotes Hepatic Fibrosis in the Animal Model. Lab Invest 2009;89:1291-1303.

23. Seki E, De Minicis S, Osterreicher $\mathrm{CH}$, et al. TLR4 enhances TGF-beta signaling and hepatic fibrosis. Nat Med 2007;13:1324-1332.

24. Vogel S, Piantedosi R, Frank J, et al. An immortalized rat liver stellate cell line (HSC-T6): a new cell model for the study of retinoid metabolism in vitro. J Lipid Res 2000;41:882-893.

25. Xia Z, Dickens M, Raingeaud J, et al. Opposing effects of ERK and JNK-p38 MAP kinases on apoptosis. Science 1995;270:1326-1331.

26. Marra F, Efsen E, Romanelli RG, et al. Ligands of peroxisome proliferator-activated receptor gamma modulate profibrogenic and proinflammatory actions in hepatic stellate cells. Gastroenterology 2002;119:466-478.

27. Naumann $M$, Rudel $T$, Wieland $B$, et al. Coordinate activation of activator protein 1 and inflammatory cytokines in response to Neisseria gonorrhoeae epithelial cell contact involves stress response kinases. J Exp Med 1998;188:1277-1286.

28. Zhang $M$, Fraser D, Phillips A. ERK, p38, and Smad signaling pathway differentially regulate transforming growth factor-1 autoinduction in proximal tubular epithelial cells. Am J Pathol 2006;169: 1282-1293.

29. Takeda K, Akira S. TLR signaling pathways. Semi Immunol 2004;16:3-9.

30. Ki MR, Lee HR, Goo MJ, et al. Differential regulation of ERK1/2 and p38 MAP kinases in VacA-induced apoptosis of gastric epithelial cells. Am J Physiol Gastrointest Liver Physiol 2008;294:G635-G647.

31. Cowley S, Paterson $H$, Kemp P, et al. Activation of MAP kinase kinase is necessary and sufficient for PC12 differentiation and for transformation of NIH 3T3 cells. Cell 1994;77:841-852.

32. Rancourt RC, Hayes DD, Chess PR, et al. Growth arrest in G1 protects against oxygen-induced DNA damage and cell death. J Cell Physiol 2002;193:26-36.

33. Reeves $\mathrm{HL}$, Dack $C L$, Peak $M$, et al. Stress-activated protein kinases in the activation of rat hepatic stellate cells in culture. J Hepatol 2000;32:465-472.

34. Huber MA, Denk A, Peter RU, et al. The IKK- $2 / \mathrm{l} \kappa \mathrm{B} \alpha / \mathrm{NF} \kappa \mathrm{B}$ pathway plays a key role in the regulation of CCR3 and eotaxin-1 in fibroblasts. A critical link to dermatitis in $\mid \kappa \mathrm{B} \alpha$-deficient mice. J Biol Chem 2002;277:1268-1275.

35. Tanos T, Marinissen MJ, Leskow FC, et al. Phosphorylation of c-Fos by members of the p38 MAPK family. Role in the AP-1 response to UV light. J Biol Chem 2005;280:18842-18852.

36. Carmiel-Haggai M, Cederbaum Al, Nieto N. A high-fat diet leads to the progression of non-alcoholic fatty liver disease in obese rats. FASEB J 2005;19:136-138.
37. Abdel-Hady H, Zaki A, Badra G, et al. Helicobacter pylori infection in hepatic encephalopathy: relationship to plasma endotoxins and blood ammonia. Hepatol Res 2007;37:1026-1033.

38. Su GL. Lipopolysaccharides in liver injury: molecular mechanisms of Kupffer cell activation. Am J Physiol Gastrointest Liver Physiol 2002;283:G256-G265.

39. Bataller R, Brenner DA. Liver fibrosis. J Clin Invest 2005;115:209-218.

40. Yoshida K, Matsuzaki K, Mori S, et al. Transforming growth factor-beta and platelet-derived growth factor signal via c-Jun N-terminal kinasedependent Smad2/3 phosphorylation in rat hepatic stellate cells after acute liver injury. Am J Pahtol 2005;164:1029-1039.

41. Carlson ME, Conboy MJ, Hsu M, et al. Relative roles of TGF-beta1 and Wnt in the systemic regulation and aging of satellite cell responses. Aging Cell 2009;8:676-689.

42. Nakagawa H, Maeda S, Hikiba $Y$, et al. Deletion of apoptosis signalregulating kinase 1 attenuates acetaminophen-induced liver injury by inhibiting c-Jun N-terminal kinase activation. Gastroenterology 2008;135:1311-1321.

43. Ip YT, Davis RJ. Signal transduction by c-Jun N-terminal kinase (JNK)-from inflammation to development. Curr Opin Cell Biol 1998;10:205-219.

44. Guo YL, Baysal K, Kang B, et al. Correlation between sustained c-Jun $\mathrm{N}$-terminal protein kinase activation and apoptosis induced by tumor necrosis factor-alpha in rat mesangial cells. J Biol Chem 1998;273: 4027-4034

45. Schwabe RF, Bradham CA, Uehara T, et al. c-Jun-N-terminal kinase drives cyclin D1 expression and proliferation during liver regeneration. Hepatology 2003;37:824-832.

46. Kluwe J, Pradere JP, Gwak GY, et al. Modulation of hepatic fibrosis by c-Jun-N-terminal kinase inhibition. Gastroenterology 2010;138:347-359.

47. Sommerfeld A, Reinehr R, Häussinger D. Bile acid-induced epidermal growth factor receptor activation in quiescent rat hepatic stellate cells can trigger both proliferation and apoptosis. J Biol Chem 2009;284:22173-22183.

48. Wheeler MD, Kono $H$, Yin $M$, et al. The role of Kupffer cell oxidant production in early ethanol-induced liver disease. Free Radic Biol Med 2001;31:1544-1549.

49. García-Trevijano ER, Iraburu MJ, Fontana L, et al. Transforming growth factor beta1 induces the expression of alpha1(I) procollagen mRNA by a hydrogen peroxide-C/EBPbeta-dependent mechanism in rat hepatic stellate cells. Hepatology 1999;29:960-970.

50. Spolarics Z. Endotoxin stimulates gene expression of ROS-eliminating pathways in rat hepatic endothelial and Kupffer cells. Am J Physiol Gastrointest Liver Physiol 1996;270:G660-G666.

51. Yu L, Hébert MC, Zhang YE. TGF- $\beta$ receptor-activated p38 MAP kinase mediates Smad-independent TGF- $\beta$ responses. EMBO J 2002;21:37493759.

52. Heldin $\mathrm{CH}$, Landström M, Moustakas A. Mechanism of TGF- $\beta$ signaling to growth arrest, apoptosis, and epithelial-mesenchymal transition. Curr Opin Cell Biol 2009;21:166-176.

53. Cho CH, Parashurama N, Park EYH, et al. Homogeneous differentiation of hepatocytes-like cells from embryonic stem cells: applications for the treatment of liver failure. FASEB J 2008;22:898-909.

54. Kordes C, Sawitza I, Müller-Marbach A, et al. CD133+ hepatic stellate cells are progenitor cells. Biochem Biophys Res Commun 2007;352:410-417.

55. Martin de las Mulas J, Gomez-Villamandos JC, Perez J, et al. Immunohistochemical evaluation of canine primary liver carcinomas: distribution of alpha-fetoprotein, carcinoembryonic antigen, keratins and vimentin. Res Vet Sci 1995;59:124-127.

56. Berasain C, Perugorria MJ, Latasa MU, et al. The epidermal growth factor receptor: a link between inflammation and liver cancer. Exp Biol Med 2009;234:713-725. 